\title{
Magdalona Potit.
}

\section{REFLEXIONES}

\section{A Osvaldo Vicuña S. \\ I}

9) ARA tomar un real interés en una cosa es preciso dedicársele completamente. Sin embargo, en un espíritu complejo hay apetito para más de una cosa... Mas si uno se divide el placer obtenido lo es sólo a medias.

¿Qué escoger? El ejemplo de Fausto hace temer el abandonarse completamente al estudio. El ejemplo de los mundanos neurasténicos nos pone en guardia contra la vida que ellos llevan: el lujo, el amor fácil, etc.

No obstante, para aquellos que quisieran equilibrarlo todo en su existencia resulta la mediocridad acompañada de dudas, de indecisiones, de vagos pero continuos arrepentimientos.

\section{II}

Todo es preferible al vacío del alma. Esos instantes monótonos en los cuales nada nos hace vibrar, cuando se hallan nuestra inteligencia, nuestros sentimientos y 
sensaciones como bajo el influjo de un anestésico, son tan embrutecedores, tan disolventes de las fuerzas de todo el seríque uno se pregunta: ¿cómo los nervios pueden soportar esta sensación de "no sensación»? Se parece aquello a lo que experimentamos cuando un miembro dormido nos deja percibir ese vago hormigueo de la sangre suficientemente perceptible para darnos la impresión de su embotamiento.

\section{III}

Somos cada cual una lengua extranjera para nuestro vecino: de cuanto le comunicamos oye sólo los sonidos, que interpreta de una manera completamente arbitraria. Algunos hombres llamados "psicólogos» hablan muchas lenguas. Mas si existiesen medidas exactas para lo infinitamente pequeño de los matices, su calco no se ajustaría jamás completamente a la forma de las letras del alfabeto del prójimo.

\section{IV}

Cuando ya no es posible engañarnos, cuando sabemos que todo es espejismo en esta irónica existencia, ¿cómo, por qué sortilegio constreñimos al esfuerzo para asir la visión que se esfuma a cada paso? Una red de verdad nos llevaba a saber a toda costa. ;Ahora sabemos! Mas el resorte de vida se ha roto: henos aquí convertidos en estatuas de sal.

\section{V}

Aquel que sabe mirar la vida de una manera objetiva llega a ser forzosamente un solitario: acostumbrado a no encontrar sino verdades relativas, a considerar las gentes y las cosas bajo su aspecto determinado, no 
se apega ni a éstas ni a aquéllas. Permanece indiferente a sí mismo porque se juzga sólo como «hombre».

En la completa disolución del yo subjetivo el ser humano ha muerto en él, pero ha muerto engendrando un semi-dios.

\section{V}

Si un químico trata de hacer un compuesto con diferentes substancias, por el hecho de no mezclarse éstas, es decir, en lenguaje químico, de no tener afinidades, ¿podemos asegurar que no hayan cambiado bajo sus mutuas influencias?

Afirmemos solamente: nuestra vista no comprueba alteración, tampoco la percibe nuestro olfato, ni el gusto; por consiguiente la razón (ciega esclava de los sentidos) a su vez no la registra. Mas puede haber transformaciones imperceptibles o de una naturaleza extraña a nuestros medios de investigación.

\section{VII}

¿Cómo no ser indeciso si se tiene un poco de imaginación y si todos los problemas de la vida se presentan a nuestro pensamiento por todas sus faces casi simultáneamente y de manera neta, precisa?

Tantas razones se levantan para actuar en un sentido como en su contrario.

Cuando una manera de existencia nos parece atrayente, es porque no la conocemos o porque hace tiempo que no la probamos. Pero no bien la ensayamos comienza el hastío y aspiramos entonces a otra forma de vida y a otra y a otra más, que nos traen siempre su vacío final.

Aún para el amor y para el trabajo suena la hora de la saciedad.

Fausto nos dice: la ciencia es vana; no compensa del 
amor y la juventud. La experiencia y los libros nos dicen: no sin razón se pinta el amor ciego. Amar es ilusionarse y desilusionarse muy pronto.

Lo malo está en analizar. Habría que ser despreocupado y jugar a la vida cual los niños corren, cual bailan y cantan, por la sola necesidad, por el solo placer de la acción.

\section{VIII}

¿A quién debemos darle la preferencia en la comedia de la vida, al actor o al espectador? La sabiduría requiere tal vez entremezclar los dos papeles. Sin embargo el espectador que acaba de pasar algunas horas en contemplación entra a la escena forzosamente embotado. Después, cuando ha logrado agitarse lo suficiente, su imaginación mareada por la bulla se presta difícilmente a la meditación. En ese flujo y reflujo continuos del contemplar y del actuar, el alma y el cuerpo desfallecen al fin y aspiran tan sólo al sueño que libera. ¿Qué voluptuosidad la disolución completa del ser en la inconsciencia! Se querría no despertar más. Pero la aurora vuelve, la vida hormiguea nuevamente en todo el ser y se renace con júbilo. Con júbilo se ensayan de nuevo todas las fuerzas hasta agotarse otra vez. Se vuelve a meditar, entonces, sobre la vanidad de la acción; reaparece el cansancio de la mente: cada fibra del ser tiende a aniquilarse hoy como ayer. iPrisioneros de un destino fatal, enredados en el engranaje de la rueda del «eterno retornar» no es por el espacio de un día, de meses, de años que este proceso de vivir, morir, renacer, se efectúa para nosotros. ¡Habremos de dar vuelta así por siempre, por siempre, por siempre...!

\section{IX}

El hombre no resiste nunca a su deseo. Creyendo escapar a la esclavitud de éste, es sencillamente por 
sumisión a cualquier otro de sus instintos: amor propio, orgullo, cansancio, etc., que se sustrae a él, o, más bien dicho, que es sustraído.

El conocimiento consiste en el registro de las sensaciones por medio de nuestros sentidos físicos y morales. He aquí por qué, si yo pienso, puedo decir que ello es una "emoción intelectual». En efecto, ¿qué es el pensamiento sino una sensación que experimenta la inteligencia? Gozar sería entonces una pura cuestión de saber cuál o cuáles son, entre nuestros sentidos, aquellos cuya percepción está aguzada. Sucede habitualmente que uno solo es capaz de intensa vibración. A veces, no obstante, varios perciben con cierta agudeza. Filosóficamente se debe poner al mismo nivel al poeta, al artista, al filósofo, al enamorado, al libertino. No se puede, al compararlos, establecer grados de calidad entre sus goces, sino sencillamente una diferencia absoluta en cuanto a la esencia de la sensación percibida puesto que la sensación de un sentido es irreductible a la de otro (no podemos oír con la vista, ni ver con el oído...).

Todo grado de calidad que estableciéramos significaría sólo esto: El sentido al que he asignado el primer rango es el más poderoso en mí.» Es esta la razón por la cual los pensadores ponen en primera línea, llamándolas superiores, las cosas del espíritu y demuestran así que juzgan con pasión sin saber salirse de sí mismos.

\section{$\mathrm{XI}$}

La razón es la esclava de los diversos sentimientos de nuestro ser en las múltiples transformaciones que sufre a medida que evoluciona. Así cada una de nues- 
tras convicciones es la máscara de la fe bajo diferentes aspectos, de manera que nuestras opiniones no reposan sobre ninguna base sólida. Nadie puede asegurar si fué ayer cuando poseíamos la verdad, si será hoy o mañana. En el momento presente creemos siempre tenerla con nosotros.

\section{XII}

Así como en algunas enfermedades de la personalidad hay desdoblamiento de la persona, y el enfermo se imagina ser dos individuos distintos, ¿no podría suceder que el género humano sufriera una especie de desdoblamiento que le diera a la sociedad la ilusión de componerse de individuos?

¿Cuál es el límite de la conciencia? ¿Por qué me siento ser solo en el corto lapso que transcurre desde el nacimiento a la muerte? ¿Por qué me siento ser de diversas maneras: primero inconscientemente; después, entre consciente $\mathrm{e}$ inconscientemente, $\mathrm{y}$ al fin casi fuera de mí mismo?

¿Y de todos estos modos de conciencia, cuál es el verdadero?

\section{XIII}

Caminaba hacia el pasado tratando de alcanzar la parte de mi vida ya escurrida. Las tumbas por millares se levantaron con sus cruces y un ser que se me parecía de manera angustiosa multiplicó tras cada una de ellas su fúnebre silueta.

Aterrada, busqué con la mirada, como un apoyo en el presente, mi rosa ce la macirugada que se marchita cada tarde en la copa de cristal mientras llega la rosa de mañana.

Mas el inmenso campo funerario de las flores que embalsamaron cada día mi morada, a pérdida de re- 
cuerdo se extendió paralelo al cementerio de mis seres innumerables que las habían cogido. ¿Quién soy yo que cuento mis muertos?

\section{XIV}

Un reloj vivo regula dentro de mi pecho las horas que conducen al doble de medianoche.

¿Cómo podría huir el aviso de segundos hechos carne dentro del ser?

Escucho anhelante la palpitación continuada, como si mirara, por una minúscula herida mortal, mi corazón sangrar, sangrar, sangrar...

\section{$\mathrm{XV}$}

Sólo una vez he leído el libro que prefiero; sólo una vez he contemplado el cuadro que admiro. Después, en ese mismo libro, en ese mismo cuadro, hallé tan sólo parientes de estos a los que yo volvía debido al recuerdo y a un vago parecido, mas sin poder nunca despertar el muerto de su sueño eterno.

La química de la percepción varía hasta el infinito sus combinaciones. Toda impresión es virgen porque la sensibilidad, al segundo contacto, se halla traspuesta.

\section{XVI}

¿Qué importa la muerte? El cadáver nada sabrá de ella. Sólo en el minuto efímero en que la pensamos, sufrimos; después no habrá sino una eternidad de inconsciencia. Mas este minuto durante el cual meditamos sobre la muerte crea a su vez la eternidad consciente del "no ser» y solamente la no coincidencia en el saber y su realización anula el sufrimiento. 


\section{XVII}

Extendí mis manos a los dos extremos del teclado; agucé el oído hasta percibir los últimos sonidos graves $\mathrm{y}$ agudos.

En mi gesto árido abracé en el instrumento el límite de nuestro ser. iAy! cuantos sonidos en la sombra que nunca nos será dado oír.

\section{y XVIII}

¡Pobre pensamiento, cómo te agitas dentro del cráneo; cómo te golpeas contra sus paredes de hueso!

Recuerdas esas trémulas mariposas ebrias de espacio que se alocan destrozándose en vano las alas contra los vidrios y el techo de la pieza cerrada. 